\title{
Kinetika Perubahan Kualitas Fisik Buah Mangga Selama Pengeringan Beku dengan Perlakuan Pendinginan Awal dan Ketebalan Irisan
}

\author{
Kinetics of Changes in Physical Quality of Mangoes during Freeze Drying with Initial Cooling Treatment and \\ Sliced Thickness \\ Yulia Ariani*, Nursigit Bintoro, Joko Nugroho Wahyu Karyadi \\ Departemen Teknik Pertanian dan Biosistem, Fakultas Teknologi Pertanian, Universitas Gadjah Mada, \\ Jl. Flora No. 1, Bulaksumur, Yogyakarta 55281, Indonesia \\ Email: yulia.ariani26@gmail.com
}

Tanggal submisi: 14 Januari 2019; Tanggal penerimaan: 13 Agustus 2019

\begin{abstract}
ABSTRAK
Mangga (Mangifera indica L.) merupakan salah satu buah penting bagi penduduk tropis. Kerugian terbesar mangga terjadi selama periode pascapanen karena kurangnya penanganan pascapanen yang tepat dan kurangnya upaya pengolahan. Pengeringan beku adalah metode yang dianggap paling baik saat ini untuk pengawetan produk hortikultura. Metode pengeringan beku ini dapat mempertahankan struktur buah, rasa, warna, dan aroma. Pada metode ini, produk didinginkan hingga membeku selama 6 jam kemudian air dalam bentuk fasa padat dikeluarkan dari bahan secara sublimasi pada keadaan hampa udara. Penelitian ini bertujuan untuk mengetahui hasil pengeringan beku antar perlakuan variasi pretreatment dan ketebahan sehingga dapat menentukan kombinasi perlakuan yang terbaik. Mangga yang digunakan memiliki kadar kemanisan $18^{\circ}$ brix dengan ukuran $14 \mathrm{~cm} \times 8 \mathrm{~cm}$ serta berat buah rata-rata $400 \mathrm{~g}$. Dalam penelitian ini menggunakan rancangan acak lengkap (RAL) tiga faktorial $2 \times 3 \times 5$. Faktor pertama perlakuan pendinginan (tanpa freezing dan nitrogen cair). Faktor kedua ketebalan bahan $(0,5 \mathrm{~cm}, 1 \mathrm{~cm}$, dan 1,5 cm). Faktor ketiga waktu (0 jam, 9 jam, 18 jam, 27 jam, dan 36 jam). Parameter yang diamati meliputi: kadar air, tekstur, dan lightness. Perlakuan tanpa freezing dengan ketebalan $1,5 \mathrm{~cm}$ menunjukkan hasil kadar air yang rendah yaitu 7,58\% dan untuk hasil kinetika menggunakan model newtonian. Perlakuan tanpa freezing dengan ketebalan $1,5 \mathrm{~cm}$ mengalami penurunan kandungan vitamin $C$ terbesar yaitu $84,12 \%$ dan untuk hasil kinetika menggunakan model orde satu. Penurunan lightness terbesar pada perlakuan nitrogen cair dengan ketebalan $1 \mathrm{~cm}$ sebesar $74,08 \%$.
\end{abstract}

Kata kunci: Pengeringan beku; mangga; pascapanen; pretreatment

\begin{abstract}
Mango (Mangifera indica L.) is one of the important fruits for tropical residents. The biggest losses of mangoes occur during the postharvest period due to the lack of proper postharvest handling and lack of processing efforts. Frozen drying is a method that is considered the best at present for preserving horticultural products. This freeze drying method can maintain the structure, taste, color, and aroma of fruit. In this method, the product was cooled to freeze for 6 hours. The solid phase water was then removed from the material through a sublimation process in vacuum condition. This study aimed to find out the freeze drying results through various pre-treatments and thicknesses by means of determining the proper combination treatment. The mango used had a sweetness level of $18^{\circ}$ Brix with a size of $14 \mathrm{~cm} \times 8 \mathrm{~cm}$ and an average weight of $400 \mathrm{~g}$. This research was conducted using a three-factor completely randomized design of $2 \times 3 \times 5$. The first factor was the cooling treatment (non-freezing and liquid nitrogen). The second factor was the thickness of the material $(0.5 \mathrm{~cm}, 1 \mathrm{~cm}$ and $1.5 \mathrm{~cm})$. The third factor was time ( 0 hours, 9 hours, 18 hours, 27 hours and 36 hours). The observed parameters comprised of:
\end{abstract}


water content, texture, and lightness. The non-freezing treatment with $1.5 \mathrm{~cm}$ thickness showed a low water content of $7.58 \%$, and the kinetics results used the Newtonian model. It also showed the highest vitamin C decrease, that was $84.12 \%$ and the kinetics results used the first-order model. The highest lightness decrease of liquid nitrogen treatment with $1 \mathrm{~cm}$ thickness was $74.08 \%$.

Keywords: Freeze drying; mango; post-harvest; pretreatment

\section{PENDAHULUAN}

Sebagai negara tropis, Indonesia merupakan daerah yang memiliki pertumbuhan aneka ragam tanaman buah-buahan yang subur, baik itu pada daerah dataran rendah maupun pada dataran tinggi. Mangga (Mangifera indica L.) merupakan salah satu buah penting bagi penduduk tropis setelah pisang. Mangga memiliki kandungan senyawayang dapatmeningkatkan kesehatan seperti karotenoid, vitamin C, dan senyawa fenolik yang menunjukkan efek pencegahan terhadap penyakit kardiovaskular dan kanker (Pot dkk., 2003). Kerugian terbesar mangga terjadi selama periode pascapanen karena kurangnya penanganan pascapanen yang tepat dan kurangnya upaya pengolahan. Pada umumnya buah-buahan di Indonesia dapat dikonsumsi dalam bentuk segar akan tetapi dengan perkembangan zaman dan teknologi pengolahan buah-buahan ini menjadi hal penting karena sifat fisik dari buah-buahan yang mudah rusak. Beku merupakan salah satu metode pengawetan makanan yang terbaik. Proses pengeringan beku yang berhasil dapat mengawetkan sebagian besar sifat fisik awal dari material seperti bentuk, dimensi, penampakan luar, rasa, warna, aroma, tekstur, dan aktivitas biologis. Produk yang dalam keadaan kering biasanya sangat berpori, getas, higroskopis, dengan kapasitas rehidrasi yang sangat baik. Pengeringan beku umumnya lebih dapat diterima sebagai pengawet cita rasa makanan beku yang lebih baik dibandingkan dengan metode lainnya. Pengeringan beku memberikan hasil yang baik dalam hal pengawetan pangan, seperti aroma dan rasa yang tahan lama, memiliki sifat rehidrasi yang lebih baik jika dibandingkan dengan metode pengeringan lainnya. Pada saat pembekuan dengan proses pengeringan beku membutuhkan waktu 6 jam untuk mencapai suhu bahan $-18^{\circ} \mathrm{C}$. Hal ini akan membuat proses pengeringan beku semakin lama sehingga diperlukan teknik khusus untuk mempersingkat waktu pada tahap pendinginan.

Pengeringan beku adalah salah satu metode yang paling efisien untuk mempertahankan sifat fisikokimia aslinya mangga (Sogi dkk., 2014). Penuruan signifikan terjadi pada ketebalan 1 dan $2 \mathrm{~mm}$ yaitu dari $82 \%$ menjadi 25-30\% (Djaeni dkk., 2007). Pada pembekuan cepat, laju penguapan panas berjalan sangat cepat, sehingga jumlah inti kristal yang terbentuk banyak dan kecil. Pada pembekuan pangan, kristal es yang semakin kecil agar dapat terdistribusi lebih merata sangat diharapkan, sehingga tidak merubah struktur jaringan (Khadatkar dkk., 2004). Hasil penelitian sebelumnya menyatakan bahwa Belyamin (2008; 2011) dan Arlisdianto (2012) telah berhasil melakukan pengeringan beku lidah buaya (aloevera) yang mengandung kadar air sebesar 98,7\%. Pujihastuti (2009) telah melakukan pengeringan beku tomat yang mengandung kadar air sebesar 93,4\%. Marques dan Freire (2004) telah melakukan pengeringan beku nenas yang mengandung kadar air sebesar $85,30 \%$. Oleh karena itu diperlukan suatu teknik pengolahan buah mangga beku kering dengan perlakuan pendinginan awal disertai variasi ketebalan irisan buah mangga untuk mengetahui respon kualitas fisik produk kering. Tujuan dari penelitian ini adalah untuk melakukan analisis perlakuan pendingainan awal dan ketebalan irisan terhadap perubahan kualitas fisik buah mangga pada proses freeze drying, menentukan konstanta laju perubahan kinetika pengeringan beku buah mangga dengan freeze drying, dan mengetahui perbandingan hasil pengeringan beku antar perlakuan variasi ketebalan dan pendinginan awal sehingga dapat menentukan kombinasi perlakuan yang terbaik.

\section{METODE PENELITIAN}

\section{Waktu dan Lokasi Penelitian}

Pelaksanaan penelitian dilakukan pada Bulan Mei 2018 - Oktober 2018 di Laboratorium Teknik Pangan dan Pascapanen (TPP), Fakultas Teknologi Pertanian, Universitas Gadjah Mada.

\section{Alat dan Bahan}

Alat yang digunakan dalam penelitian ini yaitu Freeze Dryer dengan kapasitas max $1 \mathrm{~kg}$. Suhu pendingin $-18^{\circ}$ dengan dilengkapi heater optimal 60 ${ }^{\circ} \mathrm{C}$, serta kemampuan vakum -76 . Dimensi total alat freeze drying yaitu panjang $100 \mathrm{~cm}$, lebar $80 \mathrm{~cm}$, dan tinggi $100 \mathrm{~cm}$. Heater yang digunakan yaitu heater plat dengan daya 500 watt, tegangan $220 \mathrm{~V}$, yang terdiri dari 3 buah dan memiliki dimensi $30 \times 15 \mathrm{~cm}$. 
Pompa vakum yang digunakan dengan merk Robin Air, model/ serial 15601/ 068495, dengan power $1 / 2$ HP, kapasitas $142 \mathrm{~L} / \mathrm{M}$, tegangan yang digunakan $110-115$ V/ 220-250 V (Amerika Serikat). Thermocouple yang digunakan merupakan seri (K/J TM-903 A). Timbangan yang digunakan merk (SHIMADZU (AUW220)) dengan ketelitian $0,0001 \mathrm{~g}$. Colormeteryang digunakan seri (TES135) berfungsi untuk mengetahui nilai $L, a, b$. Texture analyzer yang digunakan model (Brookfield model CT3 10K) serial number 8695312, volt/ freq 90-265 V 50/60 $\mathrm{Hz}$, power $150 \mathrm{VA}$, diameter yang digunakan 0,2 mm, dan alat ini dibuat di Amerika Serikat. Refraktometer yang digunakan merk (HANNA Instrument). Oven yang digunakan merk Mermment. Selain itu alat yang digunakan adalah pisau dan penggaris. Bahan yang digunakan untuk penelitian ini yaitu: buah mangga (harum manis) dengan berat sekitar $400 \mathrm{~g}$ ukuran 14 $\mathrm{cm} \times 8 \mathrm{~cm}$ dan brix $18^{\circ}$. Nitrogen cair yang digunakan didapat dari Samator Yogyakarta dengan kapasitas $5 \mathrm{~L}$. Kertas bakar digunakan untuk melapisi antara rak dan bahan mangga agar tidak lengket saat pengambillan. Alumunium foil digunakan untuk menyimpan mangga beku kering hasil dari alat freeze drying.

\section{HASIL PEMBAHASAN}

\section{Kadar Air Mangga Produk Hasil Pengeringan Beku}

Buah mangga segar memiliki kandungan kadar air sebesar $+/-83 \%$. Pada proses pengeringan beku yang dilakukan dengan menggunakan alat freeze dryer.

Pada Gambar 1 dapat dilihat bahwa perlakuan pendinginan yang diberikan pada setiap level ketebalan memberikan hasil yang tidak terlalu berbeda. Pada

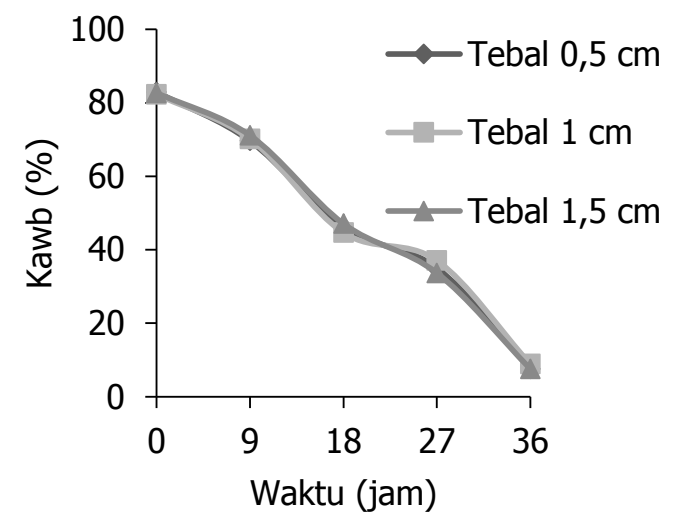

(a) parameter kadar air perlakuan tanpa freezing dengan ketebalan $1,5 \mathrm{~cm}$ menghasilkan produk mangga kering-beku yang lebih rendah yaitu $7,5 \%$. Pada kadar air gambar (b) nitrogen cair vs ketebalan 1,5 $\mathrm{cm}$ menghasilkan nilai kadar air mangga kering-beku yang lebih tinggi yaitu $14,49 \%$. Hal ini dapat dilihat bahwa semakin tinggi suhu (heater) yang diberikan, maka kadar air akhir produk mangga kering-beku akan semakin rendah terhadap ketebalan pemotongan buah. Hal ini disebabkan proses pengeringan yaitu tahap primer (sublimasi) dan tahap sekunder (desorpsi) yang berlangsung lebih cepat, terutama pada tahap pengeringan sekunder (desorpsi). Akan tetapi pada variasi pendinginan menggunakan nitrogen cair ketebalan $1,5 \mathrm{~cm}$ lebih lambat untuk menurunkan kadar air. Hal ini disebabkan semakin dingin dan tebal bahan selama pengeringan maka semakin lama proses pengeringan. Hal ini sesuai dengan penelitian (Abdillah, 2018) yang mana ketebalan bahan pengeringan sangat mempengaruhi laju pengeringan lapisan tipis pare, dimana semakin tipis bahan pengeringan maka semakin cepat terjadi laju penurunan kadar air sehingga mempengaruhi besarnya laju pengeringan.

\section{Tekstur Mangga Produk Hasil Pengeringan Beku}

Tekstur merupakan sifat yang sangat penting, baik dalam makanan segar maupun hasil olahan. Pengujian tekstur makanan merupakan upaya penemuan parameter tekstur yang tepat yang harus menjadi atribut mutu makanan yang bersangkutan, kemudian menentukan istilah populer yang paling sesuai dalam kategori parameter tersebut disertai dengan tambahan keterangan untuk menyatakan tingkatannya (Hardiman,1991).

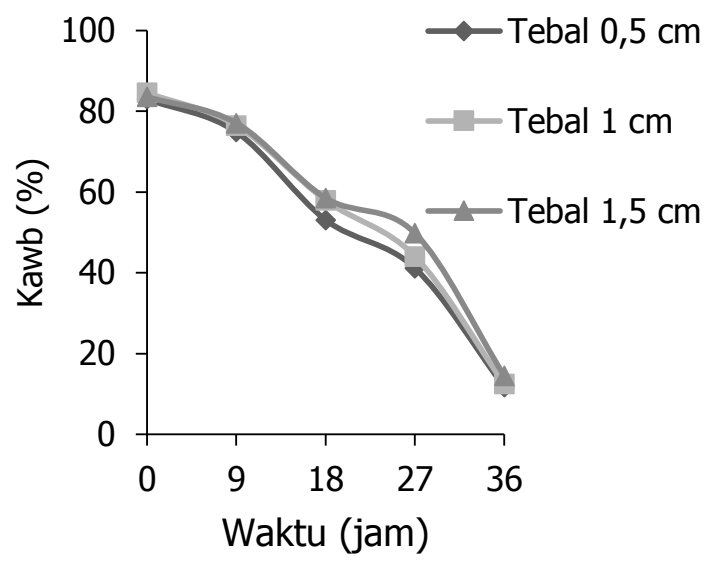

(b)

Gambar 1. Kandungan kadar air mangga selama proses kering-beku (a) tanpa freezing, (b) nitrogen cair 


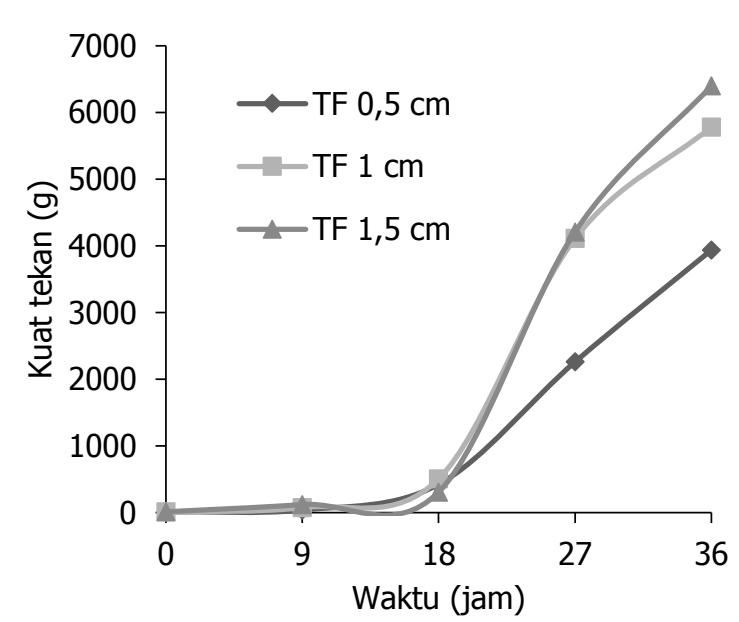

(a)

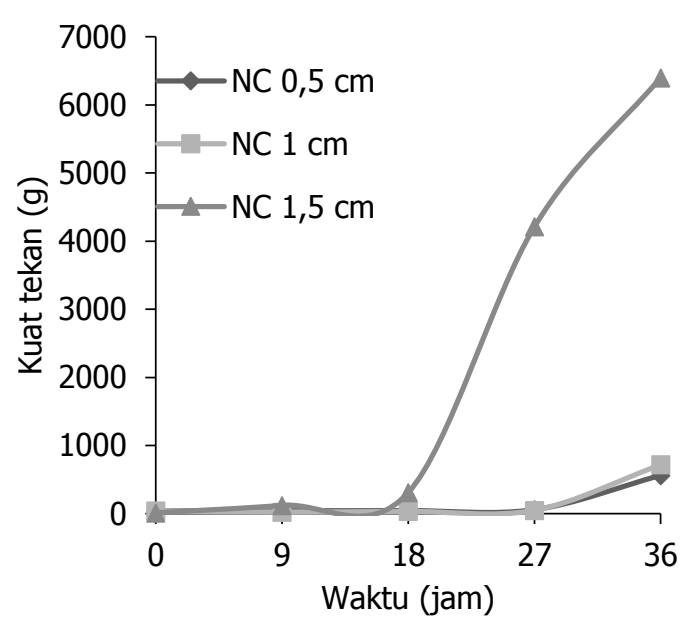

(b)

Gambar 2. Tekstur mangga selama proses kering-beku (a) tanpa freezing, (b) nitrogen cair

Pada Gambar 2 dapat dilihat bahwa perlakuan pendinginan yang diberikan pada setiap level ketebalan memberikan hasil yang berbeda. Pada parameter tekstur perlakuan tanpa freezing dengan ketebalan $0,5 \mathrm{~cm}$ menghasilkan produk mangga kering-beku yang lebih rendah yaitu sebesar 3.937,22 g, sedangkan ketebalan $1,5 \mathrm{~cm}$ menghasilkan tekstur produk mangga keringbeku yang lebih tinggi yaitu sebesar $6.398,11 \mathrm{~g}$ dan untuk ketebalan $1 \mathrm{~cm}$ menghasilkan tekstur mangga kering-beku sebesar $5.781,67 \mathrm{~g}$. Pada tekstur gambar (b) nitrogen cair vs ketebalan $1,5 \mathrm{~cm}$ menghasilkan nilai tekstur mangga kering-beku yang lebih tinggi yaitu sebesar $6.398,11 \mathrm{~g}$, sedangkan ketebalan 0,5 $\mathrm{cm}$ menghasilkan tekstur produk mangga kering-beku yang lebih rendah yaitu sebesar $561,0 \mathrm{~g}$ dan untuk ketebalan $1 \mathrm{~cm}$ menghasilkan tekstur mangga keringbeku sebesar 715,78 g. Hal ini diduga karena bahan pada tahap awal masih berbentuk fresh dan belum mengalami pengeringan sehingga memiliki nilai tekstur terendah. Sedangkan pada perlakuan pendinginan nitrogen cair ketebalan 1,5 cm dengan waktu 36 jam memiliki nilai tekstur terbaik. Hal ini diduga karena luas permukaan bahan yang digunakan semakin besar sehingga semakin cepat air di dalam bahan untuk keluar sedangkan air yang ada di bagian tengah akan merembes ke bagian permukaan dan kemudian menguap (Supriyono, 2003). Sedangkan penggunaan perlakuan nitrogen cair yaitu mempercepat proses pembekuan sehingga dapat terbentuk kristal-kristal es yang sangat kecil. Pada tahap pembekuan cepat ini jika bahan dipanaskan maka akan menyublim (berbentuk uap air) tanpa melalui proses thawing (pelelehan es). Efek kejut (shocking) dari proses pembekuan kemudian dipanaskan dengan suhu tinggi dengan proses pengeringan menyebabkan perubahan es menjadi uap sehingga pada saat pengeringan dihasilkan tekstur yang lebih renyah (crunchy) selain itu metode ini juga menghasilkan produk mangga kering-beku menjadi lebih porous hal ini disebabkan hasil mangga keringbeku yang mengembang (Nofrianti, 2013).

\section{Lightness (L)}

Lightness menunjukkan nilai kecerahan dari suatu bahan, semakin besar nilai L maka semakin cerah warnanya. Nilai $L$ menunjukkan kesan cerah atau gelap dimana tingkat kecerahan memiliki nilai antara 0 untuk warna gelap hingga 100 untuk warna cerah (putih). Akan tetapi berbanding terbalik dengan hasil penelitian mangga kering-beku semakin lama waktu pengeringan berlangsung maka nilai $L$ semakin menurun.

Pada Gambar 3 (a) tampah bahwa nilai lightness lebih tinggi yaitu 46,259 sedangkan pada Gambar 3 (b) menghasilkan produk mangga kering-beku yang lebih rendah yaitu 16,713 . Pengeringan dengan suhu yang semakin tinggi dapat menurunkan tingkat kecerahan bahan mangga kering-beku meskipun ada kenaikan sedikit pada perlakuan nitrogen cair $1 \mathrm{~cm}$ 18 jam disebabkan adanya bias pada titik pengukuran sampel dan juga dapat disebabkan oleh adanya intensitas cahaya yang lebih tinggi. Pada gambar grafik menunjukkan tren menurun hal ini disebabkan terjadinya reaksi pencoklatan karamelisasi. Hal ini sesuai dengan pendapat Zuliana dkk. (2016) yang menyatakan bahwa tingkat kecerahan dapat menurun selama proses pengeringan. 


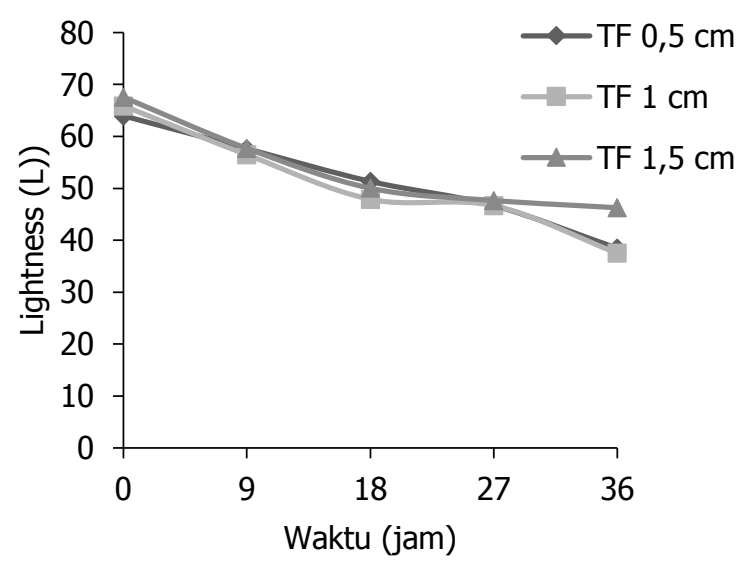

(a)

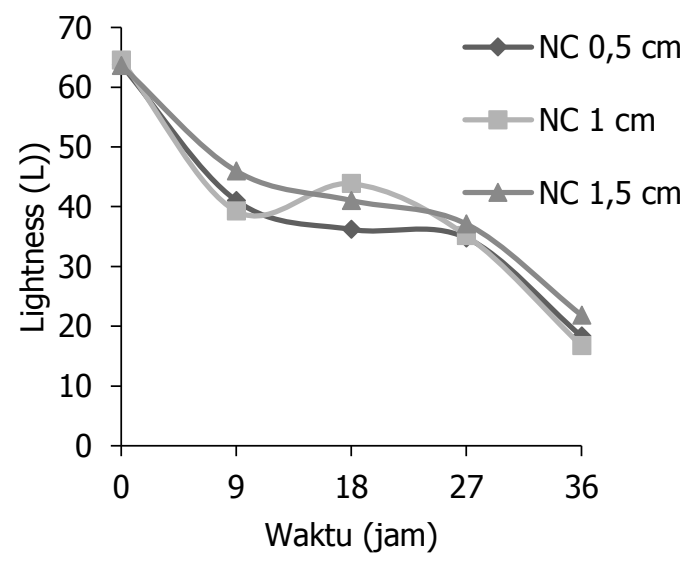

(b)

Gambar 3. Kandungan lightness mangga selama proses kering-beku (a) tanpa freezing, (b) nitrogen cair

\section{Analisis Kinetika}

\section{Kinetika perubahan kadar air}

Perubahan kadar air selama proses pengeringan beku (freeze drying) dianalisis menggunakan kinetika perubahan kadar air sehingga didapatkan nilai $k$ (konstanta laju reaksi) kadar air. Langkah pertama yang harus dilakukan yaitu, diplotkan data In kadar air C vs waktu pengeringan beku, sehingga didapatkan orde reaksi kadar air.

Pada perlakuan tanpa freezing (TF) dengan level ketebalan yang semakin tebal memiliki laju perubahan nilai $\mathrm{k}$ yang semakin naik. Hal ini menunjukkan laju penurunan kadar air pada tingkat ketebalan $1 \mathrm{~cm}$ berlangsung lebih cepat dari ketebalan yang lainnya. Pada perlakuan ketebalan $0,5 \mathrm{~cm}$ dengan peningkatan suhu yang cepat mengakibatkan bahan mengalami malilard. Proses malilard tersebut diduga menjadi penyebab lambatnya penurunan kadar air pada sampel bahan sehingga pada permukaan luar bahan mengalami pencoklatan. Hal ini ditunjukkan juga dengan penelitian
Winarno, 1997 yang menyatakan warna kecoklatan pada soy flakes merupakan hasil reaksi antara karbohidrat, khususnya gula pereduksi dengan gugus amina primer dari asam amino, reaksi ini dikenal sebagai reaksi Maillard sehingga menyebabkan kandungan air didalam bahan sulit untuk keluar. Sedangkan untuk perlakuan nitrogen cair dengan level ketebalan yang berbeda memiliki laju perubahan nilai $\mathrm{k}$ yang cenderung naik. Hal ini menunjukkan laju perubahan kadar air pada tingkat ketebalan $1,5 \mathrm{~cm}$ berlangsung lebih cepat dari ketebalan yang lainnya. Pada perlakuan ketebalan 0,5 $\mathrm{cm}$ dengan perlakuan suhu dingin yang terjadi sangat cepat menunjukkan sampel bahan mengalami efek kejut yang cepat. Efek kejut (shocking) dari proses pembekuan membuat sampel bahan menjadi retak sehingga dalam proses pengeringan kurang berjalan dengan baik. Penggunaan suhu rendah terutama untuk beberapa hasil pertanian tertentu perlu mendapat perhatian kerena kerusakan fisiologis dapat lebih cepat terjadi terutama justru pada suhu rendah, misalnya kerusakan akibat proses pendinginan (chilling injuries)

Tabel 1. Model prediksi kadar air nilai $\mathrm{k}$ dan $\mathrm{R}^{2}$ pada berbagai perlakuan

\begin{tabular}{llllll}
\hline Pendinginan & Ketebalan & Model Prediksi & & Nilai $\mathrm{k}$ & Nilai validasi $\mathrm{R}^{2}$ \\
\hline TF & $0,5 \mathrm{~cm}$ & $\mathrm{Ka}=\mathrm{e}^{-0,5 . \mathrm{t}} \times \mathrm{Ko}$ & $\mathrm{n}=1$ & $-0,5$ & 0,8896 \\
& $1 \mathrm{~cm}$ & $\mathrm{Ka}=\mathrm{e}^{-0.47 . \mathrm{t}} \times \mathrm{Ko}$ & $\mathrm{n}=1$ & $-0,047$ & 0,8908 \\
& $1,5 \mathrm{~cm}$ & $\mathrm{Ka}=\mathrm{e}^{-0.0501 . \mathrm{t}} \times \mathrm{Ko}$ & $\mathrm{n}=1$ & $-0,0501$ & 0,8832 \\
$\mathrm{NC}$ & $0,5 \mathrm{~cm}$ & $\mathrm{Ka}=\mathrm{e}^{-0.0405 . \mathrm{t}} \times \mathrm{Ko}$ & $\mathrm{n}=1$ & $-0,0405$ & 0,8637 \\
& $1 \mathrm{~cm}$ & $\mathrm{Ka}=\mathrm{e}^{-0.0388 . \mathrm{t}} \times \mathrm{Ko}$ & $\mathrm{n}=1$ & $-0,0388$ & 0,8412 \\
& $1,5 \mathrm{~cm}$ & $\mathrm{Ka}=\mathrm{e}^{-0.0346 . \mathrm{t}} \times \mathrm{Ko}$ & $\mathrm{n}=1$ & $-0,0346$ & 0,8175 \\
\hline
\end{tabular}


dan kerusakan proses pembekuan (freezing injuries). Evaluasi terhadap persamaan model kinetika dilakukan dengan menghitung nilai koefisien diterminasi $\left(R^{2}\right)$ dari data observasi dan data prediksi yang diperoleh. Dengan melakukan evaluasi terhadap nilai $\mathrm{R}^{2}$ dapat disimpulkan bahwa persamaan yang didapatkan dari model kinetika orde satu tersebut cukup baik dan dapat digunakan. Pada Tabel 1 menjelaskan bahwa model prediksi kadar air nilai $\mathrm{k}$ dan $\mathrm{R}^{2}$ yang terbaik pada perlakuan Tanpa Freezing dengan ketebalan $1 \mathrm{~cm}$

\section{Kinetika Perubahan Tekstur}

Perubahan tekstur selama proses pengeringan beku (freeze drying) dianalisis menggunakan kinetika perubahan tekstur sehingga didapatkan nilai k (konstanta laju reaksi) tekstur. Langkah pertama yang harus dilakukan yaitu, diplotkan data In tekstur vs waktu pengeringan beku, sehingga didapatkan orde reaksi tekstur.

Pada perlakuan tanpa freezing (TF) dengan level ketebalan yang semakin tebal memiliki laju perubahan nilai $k$ yang sama. Hal ini menunjukkan laju pengeringan terhadap tekstur pada tingkat ketebalan $0,5 \mathrm{~cm}, 1 \mathrm{~cm}$ dan $1,5 \mathrm{~cm}$ menunjukkan nilai k yang sama. Sedangkan untuk perlakuan Nitrogen Cair dengan level ketebalan yang berbeda memiliki laju perubahan nilai $k$ yang cenderung semakin besar. Hal ini menunjukkan laju perubahan nilai $\mathrm{k}$ pada parameter tekstur dengan tingkat ketebalan $1,5 \mathrm{~cm}$ berlangsung lebih cepat dari ketebalan yang lainnya. Pada perlakuan ketebalan 0,5 $\mathrm{cm}$ dengan perlakuan suhu dingin yang terjadi sangat cepat menunjukkan sampel bahan mengalami efek kejut yang cepat sehingga mengakibatkan bahan sampel mengalami cracking. Cracking atau terbentuknya retakan pada permukaan hingga bagian dalam produk juga bisa terjadi, terutama ketika produk makanan dibekukan dengan cara direndam ke dalam cairan pendingin atau cryogen yang menyebabkan terbentuknya lapisan beku di permukaan makanan. Lapisan ini melawan peningkatan volume dari dalam sehingga produk akan mengalami stress di bagian dalamnya. Jika lapisan beku yang terbentuk cukup rapuh, akan terjadi retakan. Pada proses pembekuan cepat (cryogenic) dengan nitrogen cair, pendinginan cepat perlu dilakukan teknik yang tepat untuk mencegah keretakan akibat turunnya temperatur secara drastis karena produk sampel mengalami kerusakan yang sangat cepat ketika terendam dalam cryogen. Efek kejut (shocking) dari proses pembekuan membuat sampel bahan menjadi retak sehingga dalam proses pengeringan dengan ketebalan $0,5 \mathrm{~cm}$ kurang berjalan dengan baik. Penggunaan suhu rendah terutama untuk beberapa hasil pertanian tertentu perlu mendapat perhatian kerena kerusakan fisiologis dapat lebih cepat terjadi terutama justru pada suhu rendah, misalnya kerusakan akibat proses pendinginan (chilling injuries) dan kerusakan proses pembekuan (freezing injuries). Hal ini berbeda dengan perlakuan ketebalan $1,5 \mathrm{~cm}$ karena bahan sampel lebih toleran terhadap proses pembekuan cepat. Evaluasi terhadap persamaan model kinetika dilakukan dengan menghitung nilai koefisien diterminasi $\left(R^{2}\right)$ dari data observasi dan data prediksi yang diperoleh. Dengan melakukan evaluasi terhadap nilai $\mathrm{R}^{2}$ dapat disimpulkan bahwa persamaan yang didapatkan dari model kinetika orde satu dan orde dua cukup baik dan dapat digunakan. Pada tabel 2 menjelaskan bahwa model prediksi tekstur nilai $\mathrm{k}$ dan $\mathrm{R}^{2}$ yang terbaik pada perlakuan Tanpa Freezing dengan ketebalan $1,5 \mathrm{~cm}$.

\section{Kinetika Perubahan Lightness (L)}

Perubahan Lightness selama proses pengeringan beku (freeze drying) dianalisis menggunakan kinetika perubahan kadar air sehingga didapatkan nilai $k$ (konstanta laju reaksi) Lightness. Langkah pertama yang harus dilakukan yaitu, diplotkan data In Lightness $\mathrm{C}$ vs waktu pengeringan beku, sehingga didapatkan orde reaksi terhadap parameter Lightness.

Tabel 2. Model prediksi tekstur nilai $k$ dan $\mathrm{R}^{2}$ pada berbagai perlakuan

\begin{tabular}{llllcc}
\hline Pendinginan & Ketebalan & \multicolumn{1}{c}{ Model prediksi } & & Nilai k & Nilai validasi $^{2}$ \\
\hline TF & $0,5 \mathrm{~cm}$ & $\mathrm{Tk}=\frac{1}{(-0,0032 * t)+\left(\frac{1}{T o}\right)}$ & $\mathrm{n}=2$ & $-0,0032$ & 0,9808 \\
& $1 \mathrm{~cm}$ & $\mathrm{Tk}=\frac{1}{(-0,0032 * t)+\left(\frac{1}{T o}\right)}$ & $\mathrm{n}=2$ & $-0,0032$ & 0,9947 \\
& $1,5 \mathrm{~cm}$ & $\mathrm{Tk}=\frac{1}{(-0,0032 * t)+\left(\frac{1}{\mathrm{To}}\right)}$ & $\mathrm{n}=2$ & $-0,0032$ & 0,9995 \\
\hline $\mathrm{NC}$ & $0,5 \mathrm{~cm}$ & $\mathrm{Tk}=\frac{1}{(-0,0008 * t)+\left(\frac{1}{T o}\right)}$ & $\mathrm{n}=2$ & $-0,0008$ & 0,8991 \\
& $1 \mathrm{~cm}$ & $\mathrm{Tk}=\frac{1}{(0,053 * t)+\left(\frac{1}{T o}\right)}$ & $\mathrm{n}=1$ & 0,053 & 0,8155 \\
& $1,5 \mathrm{~cm}$ & $\mathrm{Tk}=\frac{1}{(0,1577 * t)+\left(\frac{1}{T o}\right)}$ & $\mathrm{n}=1$ & 0,1577 & 0,9745 \\
\hline
\end{tabular}


Tabel 3. Model prediksi Lightneess nilai $\mathrm{k}$ dan $\mathrm{R}^{2}$ pada berbagai perlakuan

\begin{tabular}{|c|c|c|c|c|c|}
\hline Pendinginan & Ketebalan & Model prediksi & & Nilai k & Nilai validasi $\mathrm{R}^{2}$ \\
\hline \multirow[t]{3}{*}{ TF } & $0,5 \mathrm{~cm}$ & $\mathrm{Li}=\mathrm{e}^{-0.0131 . \mathrm{t}} \times \mathrm{Lo}$ & $\mathrm{n}=1$ & $-0,0131$ & 0,9856 \\
\hline & $1 \mathrm{~cm}$ & $\mathrm{Li}=\mathrm{e}^{-0.0151 . \mathrm{t}} \times \mathrm{Lo}$ & $\mathrm{n}=1$ & $-0,0151$ & 0,9686 \\
\hline & $1,5 \mathrm{~cm}$ & $\mathrm{Li}=\mathrm{e}^{-0.0123 . \mathrm{t}} \times \mathrm{Lo}$ & $\mathrm{n}=1$ & $-0,0123$ & 0,9222 \\
\hline \multirow[t]{3}{*}{ NC } & $0,5 \mathrm{~cm}$ & $\mathrm{Li}=\mathrm{e}^{-0.0312 . \mathrm{t}} \times \mathrm{LO}$ & $\mathrm{n}=1$ & $-0,0312$ & 0,907 \\
\hline & $1 \mathrm{~cm}$ & $\mathrm{Li}=\mathrm{e}^{-0.033 . \mathrm{t}} \times \mathrm{LO}$ & $\mathrm{n}=1$ & $-0,033$ & 0,8734 \\
\hline & $1,5 \mathrm{~cm}$ & $\mathrm{Li}=\mathrm{e}^{-0.0263 . \mathrm{t}} \times \mathrm{Lo}$ & $\mathrm{n}=1$ & $-0,0263$ & 0,9353 \\
\hline
\end{tabular}

Pada perlakuan tanpa freezing (TF) dengan level ketebalan yang semakin tebal memiliki laju perubahan nilai $k$ cenderung menurun. Hal ini menunjukkan laju pengeringan terhadap lightness pada tingkat ketebalan $0,5 \mathrm{~cm}$ dan $1 \mathrm{~cm}$ menunjukkan laju penurunan - Sedangkan untuk perlakuan ketebalan $1,5 \mathrm{~cm}$ memiliki laju perubahan nilai $\mathrm{k}$ yang cenderung naik. Hal ini menunjukkan laju kenaikan lightness pada tingkat ketebalan $1,5 \mathrm{~cm}$ berlangsung lebih cepat dari ketebalan yang lainnya. Sedangkan pada ketebalan $1,5 \mathrm{~cm}$ menunjukkan laju perubahan nilai $\mathrm{k}$ yang semakin tinggi. Hal ini menunjukkan bahwa semakin besar laju perubahan nilai $\mathrm{k}$ pada parameter lightness cenderung lebih cepat. Akan tetapi perlakuan nitrogen cair menunjukkan hasil yang berbeda yang mana perlakuan ketebalan $0,5 \mathrm{~cm}$ dan $1 \mathrm{~cm}$ menunjukkan laju penurunan terhadap parameter lightness. Hal ini sesuai dengan pendapat Zuliana dkk. (2016) yang menyatakan bahwa tingkat kecerahan dapat menurun selama proses pengeringan. Warna coklat terjadi karena proses pemanasan yang dilakukan pada saat pengeringan sehingga gula yang terdapat dalam bahan sampel mangga akan melebur di atas titik leburnya dan terjadi pencoklatan. Proses pemanasan yang berlangsung terus menerus menyebabkan sebagian besar air menguap yang menyebabkan karamelisasi. Perubahan warna tersebut disebabkan karena zat warna alami pada bahan tidak tahan terhadap suhu tinggi (Buckle dkk., 2010). Evaluasi terhadap persamaan model kinetika dilakukan dengan menghitung nilai koefisien diterminasi $\left(R^{2}\right)$ dari data observasi dan data prediksi yang diperoleh. Dengan melakukan evaluasi terhadap nilai $\mathrm{R}^{2}$ dapat disimpulkan bahwa persamaan yang didapatkan dari model kinetika orde satu cukup baik dan dapat digunakan. Pada tabel 3 menjelaskan bahwa model prediksi Lightneess nilai $\mathrm{k}$ dan $\mathrm{R}^{2}$ pada berbagai perlakuan yang terbaik pada perlakuan Tanpa Freezing dengan ketebalan 0,5 cm.

\section{KESIMPULAN}

Perlakuan tanpa freezing (TF) dengan ketebalan $0,5 \mathrm{~cm}$ menghasilkan produk mangga kering-beku yang lebih rendah yaitu $8,23 \%$. Pada perlakuan ketebalan $0,5 \mathrm{~cm}$ dengan peningkatan suhu yang cepat mengakibatkan bahan mengalami malilard. Perlakuan tanpa freezing ketebalan $1,5 \mathrm{~cm}$ menghasilkan tekstur produk mangga kering-beku yang sama besar dengan nitrogen cair ketebalan 1,5 cm sebesar $6398,11 \mathrm{~g}$. Hal ini diduga karena luas permukaan bahan yang digunakan semakin besar sehingga semakin cepat air didalam bahan untuk keluar sedangkan air yang ada di bagian tengah akan merembes ke bagian permukaan dan kemudian menguap. Perlakuan nitrogen cair dengan level ketebalan yang berbeda memiliki laju perubahan nilai $k$ yang cenderung semakin besar. Model kinetika untuk parameter tekstur menggunakan orde dua dan orde satu. Pengeringan dengan suhu yang semakin tinggi dapat menurunkan tingkat kecerahan bahan mangga kering-beku meskipun ada kenaikan sedikit pada perlakuan nitrogen cair $1 \mathrm{~cm} 18$ jam disebabkan adanya bias pada titik pengukuran sampel dan juga dapat disebbkan karena adanya intensitas cahaya yang lebih tinggi. Persamaan yang didapatkan dari model kinetika orde satu cukup baik dan dapat digunakan.

\section{KONFLIK KEPENTINGAN}

Penulis menyatakan tidak ada konflik atau kepentingan dengan pihak lain.

\section{DAFTAR PUSTAKA}

Abdillah. (2018). Model Pengeringan Lapisan Tipis Irisan Pare. Fakultas Pertanian. Makassar: Universitas Hasanuddin Makasar. 
Belyamin. (2008). Kajian Energi Pengering Beku dengan Penerapan Pembekuan Vakum dan Pemanasan Dari Bawah. Bogor: Institut Pertanian Bogor.

Belyamin. (2011). Pengembangan Pengering Beku Pembekuan Vakum dengan Pemanasan Kondensor. Bogor: Institut Pertanian Bogor.

Buckle, K. A, Edwards, R. A, Fleet, G. H., \& Wotton M. (2010). Food Science. Penerjemah Hari Purnomo dan Adiono dalam Ilmu Pangan. Jakarta: Universitas Indonesia.

Djaeni, M., Bartels, P., Sanders, J., Straten, G. Ban., \& Boxtel, A. J. B. van. (2007). Process integration for food drying with air dehumidified by zeolites. Drying Technology, 25(1), 225-239. DOI: 10.1080/07373930601161096

Hardiman. (1991). Kumpulan Hangout: Tekstur Pangan. PAU Pangan dan Gizi UGM. Yogyakarta: Gadjah Mada University Press.

Khadatkar R. M., Kumar, S., \& Pat tanjak, S. C. (2004). Cryofreezing and cryofreezer. Cryogenics, 44, 661-678.

Marques, L. G. \& Freire, J. T. (2004). Analysis of Freeze Drying of Pineapple and Guava Pulps. Brazil: Federal University of São Carlos.

Nofrianti, R. (2013). Metode Freeze Drying Bikin Keripik Makin Crunchy. Program Pasca Sarjana, Program Studi Ilmu Pangan. Bogor: Institut Pertanian Bogor.
Supriyono. (2003). Mengukur Faktor-Faktor dalam Proses Pengeringan. Jakarta: Gramedia.

Pot, I., Marx, M., Neidhart, S., Muhlbauer, W., \& Carle, R. (2003). Quantitative determination of $\beta$-carotene stereoisomers in fresh, dried, and solar-dried mangoes (Mangifera indica L.). Journal of Agricultural and Food Chemistry, 51. DOI:10.1021/jf034084h

Pujihastuti, I. (2009). Teknologi Pengawetan Buah Tomat dengan Metode Freeze Drying. Semarang: Universitas Diponegoro.

Sogi, D. S. \& Oberoi, D. P. S. (2015). Effect of drying methods and maltodekstrin concentration on pigment content of watermelon juice powder. Journal of Food Engineering, 105(2015), 172-178. http://dx.doi.org/10.1016

Valentas, K.J., Rotstein, E. \& Sing, R.P. 1997. Handbook of Food Engineering Practice. New York: CRC Press.

Winarno, F. G. (1997). Kimia Pangan dan Gizi. Jakarta: PT. Gramedia Pustaka Utama.

Zuliana. (2016). Pembuatan gula semut kelapa (kajian pH gula dan kelapa dan konsentrasi natrium bikarbonat. Jurnal Pangan dan Agroindustri, 4(1), 109-119. 